Department of Economics- FEA/USP

\title{
Observability and Endogenous Organizations
}

Gabriel de Abreu Madeira 


\author{
DEPARTMENT OF ECONOMICS, FEA-USP \\ WORKING PAPER № 2015-05
}

\title{
Observability and Endogenous Organizations
}

\author{
Gabriel de Abreu Madeira (gmadeira@usp.br)
}

\begin{abstract}
:
This paper establishes a relationship between the observability of common shocks and optimal organizational design in a multiagent moral hazard environment. We consider two types of organizations, namely relative-performace and cooperative regimes, and show that, with sufficient information regarding common shocks, a cooperative organization can be optimal even if outputs are highly correlated. The model is then embedded in a Walrasian general equilibrium model in which choices regarding organizations and investment in information on common shocks are jointly determined. Numerical results reveal that both cooperative and relative-performance regimes can coexist in equilibrium but only cooperative organizations invest in full observability of common shocks. Changes in the cost of information and aggregate wealth can affect substantially the types of organizations operating and the matching patterns of heterogeneous agents in these organizations. General equilibrium effects are key in determining how information costs impact on the way production is organized.
\end{abstract}

Keywords: organizational design; observability; relative performance regime; group regime; general equilibrium; value of information.

JEL Codes: D23; D71; D85; 017. 


\title{
Observability and Endogenous Organizations*
}

\author{
Weerachart T. Kilenthong \\ University of the Thai Chamber of Commerce \\ Gabriel A. Madeira \\ Universidade de São Paulo \\ September 10, 2015
}

\begin{abstract}
This paper establishes a relationship between the observability of common shocks and optimal organizational design in a multiagent moral hazard environment. We consider two types of organizations, namely relative-performace and cooperative regimes, and show that, with sufficient information regarding common shocks, a cooperative organization can be optimal even if outputs are highly correlated. The model is then embedded in a Walrasian general equilibrium model in which choices regarding organizations and investment in information on common shocks are jointly determined. Numerical results reveal that both cooperative and relative-performance regimes can coexist in equilibrium but only cooperative organizations invest in full observability of common shocks. Changes in the cost of information and aggregate wealth can affect substantially the the types of organizations operating and the matching patterns of heterogeneous agents in these organizations. General equilibrium effects are key in determining how information costs impact on the way production is organized.

JEL Classification Numbers: D23; D71; D85; O17.
\end{abstract}

\footnotetext{
*Tee Kilenthong would like to thank the University of the Thai Chamber of Commerce for the financial support. Tee Kilenthong's email: tee@riped.utcc.ac.th. Gabriel Madeira's email: gabriel.madeira@gmail.com.
} 
Keywords: organizational design, observability, relative performance regime, group regime, general equilibrium, value of information

\section{Introduction}

This paper examines how the observability of common production shocks that concurrently affect multiple agents influences an optimal organization design. We consider an organization as contractual arrangements between multiple individuals, who are engaged in production subject to moral hazard, and an outsider/principal. Two alternative organizational regimes are considered. In the first one, individuals act cooperatively, sharing information and taking joint decisions subject to collective incentives. This type of organization represents teamwork or joint liability credit contracts, which encourage cooperation among agents, to take advantage of their capacity to interact and share information (e.g., Lazear and Shaw, 2007; Ghatak and Guinnane, 1999). In the second regime, individuals compete in response to individualistic incentives, possibly based on relative performance. This regime includes job tournaments and relative-performance compensation schemes, which stimulate competition among agents under comparative evaluation (e.g., Lazear and Rosen, 1981; Barlevy and Neal, 2012).

We propose a framework that extends the standard multiagent moral hazard literature (e.g., Holmstrom and Milgrom, 1990; Ramakrishnan and Thakor, 1991; Itoh, 1993; Prescott and Townsend, 2002) to incorporate partial observability of common shocks. This literature identifies output correlation as the key ingredient in determining an optimal organizational regime. In our formulation, output correlation emerges as a consequence of the presence of common shocks. This feature allows us to analyze the role of the (potentially costly) observability of common shocks. Although some small events may remain impossible to observe at a reasonable cost, larger events, especially those that simultaneously affect multiple agents, are arguably observable at a certain cost. Examples include the measurement of weather conditions for index insurers, and the measurement of sector productivity by sectoral consultants.

We show that the observability of common shocks is a key determinant of optimal organi- 
zational schemes. Cooperation has the advantage of allowing agents to make joint decisions regarding mutually observable and enforceable actions that are unobserved by outsiders. However, cooperating agents can collude in such a way that undermines incentives. Collusion will be particularly harmful if the common shocks are unobserved. This is because it is difficult for an outsider to distinguish an adverse aggregate event from the coordinated neglect of agents. By contrast, in a relative performance scheme, each individual's output/performance is informative with respect to the common shocks that affect all agents. Thus, unobserved common shocks provide an advantage for the relative performance compensation regime over the cooperation regime.

This paper shows that cooperation is optimal when the common shocks are perfectly observable, regardless of the correlation structure of outputs or the structure of common shocks. This finding helps explain the empirical observation that cooperative arrangements are sometimes highly prevalent even when outputs are highly correlated (Ahlin and Townsend, 2007). Indeed, according to our results, this pattern will be observed if the correlation of outputs is driven by observable and contractible common events. Furthermore, our results indicate that the emergence of cooperative behaviors can be a consequence of an improvement in observability of common shocks. For a symmetric case in which individuals are ex ante identical, we can prove that a cooperative or group regime prevails when the common shocks are perfectly observable. In another polar case in which all shocks are common and punishment can be arbitrarily severe, relative performance will always dominate, regardless of the information structure. This result emphasizes the role of idiosyncratic shocks in group collective arrangements.

We characterize optimal organizational regimes in two stages. First, we determine surplus maximizing multiagent contracts as functions of outside options for each members and the amount of (costly) information regarding the common shocks. The resulting contracts are interpreted as potential firms or organizations. Then, following Prescott and Townsend (2006), we formulate and solve the assignment problem of a continuum of individuals into these organizations. A solution to this assignment problem is Pareto efficient, and can be decentralized as Walrasian equilibria.

Numerical solutions of general equilibria have been provided for several levels of risk 
aversion and technologies, showing how organizations respond to changes in the cost of information and wealth. In all of these specifications, when the cost of information about common shocks is sufficiently low, all firms invest in information and adopt cooperative arrangements. With higher costs of information, some firms operate without investment in information and relative performance arrangements can be observed. For a given cost of information, wealth is also relevant to determine weather information is acquired or not. Poor economies are less likely to purchase information, since investment in information requires sacrifice of consumption. Economies with rich agents also have a low probability of purchasing information, since information about common shocks are an incentive tool, and rich agents typically make lower effort. So information is more likely to be purchased in an intermediary wealth range.

For some of the specifications computed, we present contractual details such as the levels of effort and heterogeneity of agents inside organization. Our results reveal a complex interaction between wealth, inequality, effort, and information determining equilibrium allocations. Small changes in the cost of information or wealth can generate dramatic reshaping in the contracts operating, and general equilibrium and matching effects are important forces behind these abrupt changes.

Our numerical results reveal that distinct contractual arrangements can co-exist in equilibrium: some individuals will be assigned to cooperative/group contracts and others will be assigned to relative performance contracts. This coexistence of diverse organizational regimes is observed in the real world. Data from Indian villages reveal that although some landowners have their land farmed by groups of individuals acting cooperatively, others divide their land into several plots and employ a single worker or family on each plot (e.g., Townsend and Mueller, 1998; Mueller et al., 2002). Ahlin and Townsend (2007) shows that many microcredit arrangements are one-per-credit contracts, but joint liability credit contracts have also been widely adopted in Thai villages. Some firms employ teamwork, whereas others adopt individualistic incentive schemes (Lazear and Shaw, 2007).

Our examples also suggest that only cooperative organizations invest in full information about common shocks. Since investment in information can be interpreted as accepting or taking (insurance) contracts conditional on information regarding the common shocks, such 
as rain insurances, this result suggests that index or weather insurance issuers should target cooperative or group organizations as their main customers.

This paper belongs to a vast body of the literature on cooperative or competitive incentive schemes. Lazear and Rosen (1981) and Barlevy and Neal (2012) showed that comparative compensation may be a useful tool to create incentives when monitoring is costly or when output measurement is subtle. Ray (2007) and Genicot and Ray (2003) presented examples of the optimality of group organizations in an environment with complete information to address externalities and risk-sharing problems. Ghatak and Guinnane (1999) and Lazear and Shaw (2007) argued that cooperation and teamwork can also be useful in addressing asymmetric information problems. This literature focuses on establishing the optimality of either cooperation or competition in specific contexts. Our framework is sufficiently rich to cover cases in which either regime endogenously prevails as well as cases in which the two regimes coexist.

The model also has novel empirical implications. A transition from relative-performance to cooperative organizations should be observed if the cost of information becomes less expensive over time (possibly because of improvements in information technology). This implication is consistent with the evidence reported by Lazear and Shaw (2007), who showed that teamwork has been increasingly adopted by large companies in recent decades. Further, one can interpret the observability of common shocks as useful knowledge about the productive technology that commonly affects all individuals engaged in production. Our results therefore imply that, when a new technology is adopted, incentives should initially be generated through competitive schemes, and cooperative schemes should subsequently be adopted as the knowledge of the new technology improves.

This paper also relates to the risk-sharing literature. Although most empirical tests rejected full risk sharing within villages (Deaton, 1992; Townsend, 1994; Jalan and Ravallion, 1999), many studies showed that some groups of individuals can achieve a sufficiently high level of risk sharing (Grimard, 1997; Goldstein, 2000; Fafchamps and Gubert, 2007). Further, Chiappori et al. (2014) showed that some family networks and some villages in Thailand share risks perfectly, whereas others perform poorly. Through the lens of our model, differences in the ability to share risks may partly result from the observability of information regarding 
common shocks. That is, a group of households, who can share information better, could potentially share risk more effectively by choosing a cooperative/group contract to serve the objective, and vice versa.

The remainder of the paper is organized as follows. Section 2 describes the basic environment of the model, the informational structure, and the role of informational structure in production. Section 3 formally presents the organizational regimes, and characterizes the optimal arrangements for each regime. Section 4 formulates a Walrasian equilibrium model with endogenous organizational and informational regimes, and presents its numerical examples. Section 5 concludes the paper. Appendix A contains proofs.

\section{The Model Economy}

There are two physical commodities: a consumption good and a capital good. For the sake of simplicity, we assume that consumption can have only finite (but possibly many) level: There is a continuum of risk-averse agents that are divided into $I$ types, each of which is indexed by $i=1,2, \ldots, I$. Each type $i$ consists of an $\alpha^{i} \in(0,1)$ fraction of the population, and $\sum_{i} \alpha^{i}=1$. Each agent type $i$ is endowed with $\kappa^{i}$ units of capital. Capital endowments are the main source of heterogeneity among agents.

Each organization/firm has the same fixed number of workers. All workers of an organization encounters the same local state or the common shock, $\omega$. The state space $\Omega$ is the finite set of states of nature, and $\operatorname{Pr}(\omega)$ is the probability of state $\omega$ occurring, such that the following equation holds:

$$
\sum_{\omega \in \Omega} \operatorname{Pr}(\omega)=1
$$

Agent $i$ derives utility from consumption $c_{i}$ and effort $e_{i}$, according to the utility function $u\left(c_{i}, e_{i}\right)$. The utility function is assumed to be concave and to be strictly increasing in $c_{i}$, and decreasing in $e_{i}$. Again, we assume that effort or action can take only finite (but possibly many) values. An agent's effort is private information; therefore, there is a moral hazard

\footnotetext{
${ }^{1}$ We can apply the limiting arguments used in Prescott and Townsend (1984) to establish results when the commodity space is not finite.
} 
problem. In addition, we assume that effort is exerted before the underlying state $\omega$ can be observed. That is, effort cannot be assigned to be conditional on $\omega$.

Each agent operates an identical production technology, $f(q \mid e, k, \omega)$, which indicates the probability of obtaining output $q$ (in units of the consumption good), conditional on her effort $e$, the amount of captal inside the organization $k$ and the organization-specific production shock $\omega{ }^{2}$, Again there are finite (but possibly many) feasible levels of output. The production technology is random and thus satisfies the probability constraint:

$$
\sum_{q} f(q \mid e, k, \omega)=1, \forall e, k, \omega
$$

Agents can form a local organization whose members experience the same local underlying state or the common shock. For expositional convenience, we assume that there are only two agents in each firm, but the analysis can easily be extended to cases with any finite number of agents per firm. Let $\mathbf{q}=\left(q_{1}, q_{2}\right)$ and $\mathbf{e}=\left(e_{1}, e_{2}\right)$ denote the realized outputs and effort levels of firm members, respectively. Accordingly, we can write the ex ante and conditional joint distributions of the outputs of workers in a local organization as $\operatorname{Pr}(\mathbf{q} \mid \mathbf{e}, k)$ and $\operatorname{Pr}(\mathbf{q} \mid \mathbf{e}, k, \omega)$, respectively.

This paper assumes that the outputs of workers in a local organization are uncorrelated when conditional on the common shock $\omega$ but that they are correlated ex ante. This assumption is summarized below:

Assumption 1. The joint distribution of outputs satisfies the following conditions:

(i) outputs are independent, conditional on $\omega$ :

$$
\operatorname{Pr}\left(q_{i}, q_{j} \mid e_{i}, e_{j}, k, \omega\right)=f\left(q_{i} \mid e_{i}, k, \omega\right) f\left(q_{j} \mid e_{j}, k, \omega\right),
$$

(ii) but not independent ex ante:

$$
\begin{aligned}
\operatorname{Pr}\left(q_{i}, q_{j} \mid e_{i}, e_{j}, k\right) & =\sum_{\omega} \operatorname{Pr}(\omega) f\left(q_{i} \mid e_{i}, k, \omega\right) f\left(q_{j} \mid e_{j}, k, \omega\right) \\
& \neq \operatorname{Pr}\left(q_{i} \mid e_{i}, k\right) \operatorname{Pr}\left(q_{i} \mid e_{j}, k\right)
\end{aligned}
$$

where $\operatorname{Pr}\left(q_{i} \mid e_{i}, k\right)=\sum_{\omega} \operatorname{Pr}(\omega) f\left(q_{i} \mid e_{i}, k, \omega\right)$.

\footnotetext{
${ }^{2}$ Note that both $k$ and $\omega$ are organization-specific variables, which affect simultaneously the production functions of all workers assigned to an organization.
} 
Note that the joint distributions are well defined, i.e.,

$$
\begin{aligned}
\sum_{\mathbf{q}} \operatorname{Pr}(\mathbf{q} \mid \mathbf{e}, k, \omega) & =1, \forall \mathbf{e}, k, \omega \\
\sum_{\mathbf{q}} \operatorname{Pr}(\mathbf{q} \mid \mathbf{e}, k) & =1, \forall \mathbf{e}, k
\end{aligned}
$$

The common shock $\omega$ is not necessarily distinctly observable, and therefore may not be contractible. Nevertheless, agents may be able to distinctly identify an element of a partition of the state space $\Omega$. This partition characterizes an informational regime, which is defined more precisely in the next section.

\subsection{Informational Regimes}

An informational regime $z$ is a partition of $\Omega$, and is denoted by $F_{z}$. Let a subset $A_{s} \subset \Omega$ be a typical member of an informational regime $z$; i.e., $A_{s} \in F_{z}$. With abuse of notation, we will refer to $A_{s}$ as observed state $s$. For notational convenience, let $Z$ denote the number of distinguishable events that are non-empty subsets of $\Omega$ in $F_{z}$; i.e., $F_{z}=\left\{A_{1}, \ldots, A_{Z}\right\}$. Technically, a partition requires that $\cup_{s=1}^{Z} A_{s}=F_{z}$ and $A_{s} \bigcap A_{s^{\prime}}=\emptyset$. For example, the coarsest informational structure (containing the least amount of information regarding states of nature) is $F_{z}=\left\{\left\{\omega_{1}, \omega_{2}\right\}\right\}$. Under this informational regime, we cannot distinguish the underlying state from one another. By contrast, the finest information structure (in which we can distinguish all underlying states of nature from one another) is $F_{\bar{z}}=\left\{\left\{\omega_{1}\right\},\left\{\omega_{2}\right\}\right\}$.

For a given informational regime $F_{z}$, we can define a modified production function for each subset $A_{s} \in F_{z}$ (using Bayes' rule) as follows:

$$
\operatorname{Pr}(\mathbf{q} \mid \mathbf{e}, k, s)=\frac{\sum_{\omega \in A_{s}} \operatorname{Pr}(\mathbf{q} \mid \mathbf{e}, k, \omega) \operatorname{Pr}(\omega)}{\operatorname{Pr}\left(A_{s}\right)}
$$

where $\operatorname{Pr}\left(A_{s}\right)=\sum_{\omega \in A_{s}} \operatorname{Pr}(\omega)$ is the probability of having a common state in $A_{s}$. Note that this joint production function satisfies the following probability condition

$$
\begin{aligned}
\sum_{\mathbf{q}} \operatorname{Pr}(\mathbf{q} \mid \mathbf{e}, k, s) & =\sum_{\mathbf{q}} \frac{\sum_{\omega \in A_{s}} \operatorname{Pr}(\mathbf{q} \mid \mathbf{e}, k, \omega) \operatorname{Pr}(\omega)}{\operatorname{Pr}\left(A_{s}\right)} \\
& =\frac{\sum_{\omega \in A_{s}} \operatorname{Pr}(\omega) \sum_{\mathbf{q}} \operatorname{Pr}(\mathbf{q} \mid \mathbf{e}, k, \omega)}{\operatorname{Pr}\left(A_{s}\right)}=1
\end{aligned}
$$


where the last equation follows condition (6).

An informational regime provides information that is relevant for local production. Such information may include information regarding weather conditions or sectoral economic indicators. This type of information can be obtained at certain cost. More precisely, the informational partition can be made finer by investing in information technology.

An informational regime $F_{z}$ can be attained at a cost of $C_{z}$ units of capital. That is, the informational regime $F_{z}$ for a local organization can be made available through an (exante) investment of $C_{z}$ units of capital. This cost is assumed to be per unit of organizations participating in the regime. The cost is assumed to be increasing in terms of the accuracy of the information; i.e., $C_{z} \geq C_{z^{\prime}}$ for $F_{z} \subset F_{z^{\prime}}$. Thus, the information cost is higher when the informational regime is finer.

\section{Firms as Optimal Contracts: A Principal-Agent For- mulation}

Each individual is employed by a local organization or firm. Because workers are risk averse, they potentially benefit from risk-sharing contracts provided by the principal 3 . The moral hazard problem implies that optimal consumption depends on output in order to provide incentives for an agent to exert costly effort. In addition, an organization in this model could also mitigate the moral hazard problem by investing in an information technology that helps identify the common shock.

We consider two organizational regimes, which are formally defined below; (i) a relative performance regime and (ii) a group regime. Those are stylized regimes that are present in the existing literature (e.g., Holmstrom and Milgrom, 1990; Ramakrishnan and Thakor, 1991; Itoh, 1993; Prescott and Townsend, 2002) that can be clearly interpreted as competitive (relative performance) versus cooperative (groups) contractual arrangements.

A firm is characterized by an organizational regime, an informational regime, capital, and promised utility levels for each position in the firm. More formally, the set of potential

\footnotetext{
${ }^{3}$ In the general equilibrium formulation, principals will be modeled as competitive intermediaries.
} 
firms is defined by the following:

$$
B=\left\{b=\left(o, z, k, \bar{u}_{1}, \bar{u}_{2}\right)\right\}
$$

where $o$ is the organizational regime (relative performance or group), $z$ is the informational regime, $k$ is the firm's capital, and $\bar{u}_{i}$ is the promised utility level for an agent in position $i$ within the firm. Without loss of generality, we focus only on efficient firms. Specifically, each firm maximizes an expected surplus that is conditional on given incentives and technological constraints. The set of efficient firms, $B$, will define the commodity space in the general equilibrium model of Section 4, in which each individual will be (possibly randomly) assigned to a position within the firm. Implicitly, this assumption includes choices of organizational regimes and investment in information.

\subsection{Relative Performance Firms}

The relative performance regime features competition among agents as an incentive tool. Workers do not share information regarding their effort levels, and each agent is rewarded separately. If one agent performs poorly compared with the others, then she will be punished, but if she performs well compared with the others, then she will be rewarded. These comparative compensation schemes are particularly useful when the output of one individual is informative regarding the shocks that affect other individuals or the outputs are highly correlated.

Formally, a relative performance contract $\pi^{r}(\mathbf{c}, \mathbf{q}, \mathbf{e}, s)$ is the probability that a firm's workers will obtain consumption $\mathbf{c}=\left(c_{1}, c_{2}\right)$, produce outputs $\mathbf{q}=\left(q_{1}, q_{2}\right)$, provide effort levels $\mathbf{e}=\left(e_{1}, e_{2}\right)$, and the observed state is $s$ (or $\left.A_{s}\right)$. The subscript $i=1,2$ denotes the position of a member of the firm, and the superscript $r$ denotes the relative performance regime. To be more precise, this contract is conditional on the capital input $k$, the informational regime $z$, and promised utility levels $\left(\bar{u}_{1}, \bar{u}_{2}\right)$, which are kept implicit for notational convenience. Contract $\pi^{r}(\mathbf{c}, \mathbf{q}, \mathbf{e}, s)$ implicitly encompasses two decisions: the distribution of recommended effort $(\operatorname{Pr}(\mathbf{e}))$ and the distribution of consumption conditional on output, effort, and the observed state, $\operatorname{Pr}(\mathbf{c} \mid \mathbf{q}, \mathbf{e}, k, s)$.

The timing of events is as follows. First, workers are randomly assigned to levels of 
effort according to $\operatorname{Pr}(\mathbf{e})$. After such efforts are undertaken, some state of nature $\omega \in A_{s}$ is realized. This implies that state $s$ is observed, and the outputs $\mathbf{q}$ are obtained with probability $\operatorname{Pr}(\mathbf{q} \mid \mathbf{e}, k, s)$.

The workers then obtain consumption goods according to $\operatorname{Pr}(\mathbf{c} \mid \mathbf{q}, \mathbf{e}, k, s)$, which potentially depends on the observed information set $A_{s}$. All of these probabilities are implicit in the contract $\pi^{r}(\mathbf{c}, \mathbf{q}, \mathbf{e}, s)=\operatorname{Pr}(\mathbf{e}) \operatorname{Pr}(\mathbf{q} \mid \mathbf{e}, k, s) \operatorname{Pr}(\mathbf{c} \mid \mathbf{q}, \mathbf{e}, k, s) \operatorname{Pr}\left(A_{s}\right)$.

As a probability measure, a contract $\pi^{r}(\mathbf{c}, \mathbf{q}, \mathbf{e}, s)$ must satisfy the following probability constraint:

$$
\sum_{\mathbf{c}, \mathbf{q}, \mathbf{e}, s} \pi^{r}(\mathbf{c}, \mathbf{q}, \mathbf{e}, s)=1, \quad \text { and } \pi^{r}(\mathbf{c}, \mathbf{q}, \mathbf{e}, s) \geq 0, \forall(\mathbf{c}, \mathbf{q}, \mathbf{e}, s)
$$

A feasible contract $\pi^{r}(\mathbf{c}, \mathbf{q}, \mathbf{e}, s)$ must also be consistent with the production technology (8). The following mother nature constraint guarantees such consistency. For any vector of effort levels e and any observed state $s \in F_{z}$, such that $\sum_{\mathbf{c}, \mathbf{q}} \pi^{r}(\mathbf{c}, \mathbf{q}, \mathbf{e}, s)>0$, Bayes' rule implies the following:

$$
\frac{\sum_{\mathbf{c}} \pi^{r}(\mathbf{c}, \overline{\mathbf{q}}, \mathbf{e}, s)}{\sum_{\mathbf{c}, \mathbf{q}} \pi^{r}(\mathbf{c}, \mathbf{q}, \mathbf{e}, s)}=\operatorname{Pr}(\overline{\mathbf{q}} \mid \mathbf{e}, k, s), \forall \overline{\mathbf{q}}, \mathbf{e}, s .
$$

The mother nature constraints can be rewritten in the form of linear constraints: for a given $k$,

$$
\sum_{\mathbf{c}} \pi^{r}(\mathbf{c}, \overline{\mathbf{q}}, \mathbf{e}, s)=\operatorname{Pr}(\overline{\mathbf{q}} \mid \mathbf{e}, k, s) \sum_{\mathbf{c}, \mathbf{q}} \pi^{r}(\mathbf{c}, \mathbf{q}, \mathbf{e}, s), \forall \overline{\mathbf{q}}, \mathbf{e}, s .
$$

A feasible contract must ensure that the utility level of a worker in position $i$ is not less than the promised expected utility for that position, $\bar{u}_{i}$. This participation constraint is defined by the following:

$$
\sum_{\mathbf{c}, \mathbf{q}, \mathbf{e}, s} \pi^{r}(\mathbf{c}, \mathbf{q}, \mathbf{e}, s) u\left(c_{i}, e_{i}\right) \geq \bar{u}_{i}, \forall i .
$$

Because efforts are privately observed, a feasible contract must be incentive compatible; that is, each worker must have incentives to undertake the recommended level of effort. The incentive compatibility constraints can be formulated as follows:

$$
\begin{aligned}
\sum_{\mathbf{c}, \mathbf{q}, \mathbf{e}_{-i}, s} \pi^{r}\left(\mathbf{c}, \mathbf{q}, e_{i}, \mathbf{e}_{-i}, s\right) u\left(c_{i}, e_{i}\right) & \geq \\
& \sum_{\mathbf{c}, \mathbf{q}, \mathbf{e}_{-i}, s} \pi^{r}\left(\mathbf{c}, \mathbf{q}, e_{i}, \mathbf{e}_{-i}, s\right) \frac{\operatorname{Pr}\left(\mathbf{q} \mid \tilde{e}_{i}, \mathbf{e}_{-i}, k, s\right)}{\operatorname{Pr}\left(\mathbf{q} \mid e_{i}, \mathbf{e}_{-i}, k, s\right)} u\left(c_{i}, \tilde{e}_{i}\right), \forall e_{i}, \tilde{e}_{i},
\end{aligned}
$$


Effort level is determined before the state $s$ is observed; thus, the assignment of effort cannot be contingent on the observed state $s$. That is, for any vector of effort levels e,

$$
\sum_{\mathbf{c}, \mathbf{q}} \pi^{r}(\mathbf{c}, \mathbf{q}, \mathbf{e}, \bar{s})=\operatorname{Pr}\left(A_{\bar{s}}\right) \sum_{\mathbf{c}, \mathbf{q}, s} \pi^{r}(\mathbf{c}, \mathbf{q}, \mathbf{e}, s), \forall \bar{s} \in F_{z}
$$

Note that we can show that $\sum_{\mathbf{c}, \mathbf{q}, \mathbf{e}} \pi^{r}(\mathbf{c}, \mathbf{q}, \mathbf{e}, \bar{s})=\operatorname{Pr}\left(A_{\bar{s}}\right)$ for all $\bar{s} \in F_{z}$ using (10) and (14). That is, the contract $\pi^{r}$ is consistent with the probability distribution over the observed states in $F_{z}$.

A relative performance firm is an optimal contract $\pi^{r}(\mathbf{c}, \mathbf{q}, \mathbf{e}, s)$ that solves the following surplus maximization problem:

\section{Program 1.}

$$
\max _{\pi^{r}} \sum_{\mathbf{c}, \mathbf{q}, \mathbf{e}, s} \pi^{r}(\mathbf{c}, \mathbf{q}, \mathbf{e}, s)\left(q_{1}+q_{2}-c_{1}-c_{2}\right)
$$

subject to constraints (10), 111), 12), (13), and (14).

\subsection{Group or Cooperative Firms}

Another type of organizational scheme is a group or cooperative regime, under which decisions are made jointly by agents, who observe one another's actions and are able to offer side payments. Because the entire group can be punished for individual failures, each worker has incentives to monitor and ensure that the others exert the desired amounts of effort. However, the workers in a group firm can potentially collude/coordinate in (possibly low) effort levels and make side payments to promote local Pareto improvements. The principal anticipates this possibility and offers only collusion-proof contracts. The collusion-proof condition implies that the allocations of effort and consumption shares are optimal, given some internal (within-group) Pareto weights. This type of contract in turn implies that there is full risk sharing within groups, such that individual levels of consumption depend only on the within-group Pareto weights and the aggregate consumption level. Thus, formally, a group contract, $\pi^{g}\left(c_{a}, \mu, \mathbf{q}, \mathbf{e}, s\right)$, is the probability that the aggregate consumption is $c_{a}$, its members are assigned within-group Pareto weights $\mu=\left(\mu_{1}, \mu_{2}\right)$, their realized outputs are $\mathbf{q}=\left(q_{1}, q_{2}\right)$, their efforts are $\mathbf{e}=\left(e_{1}, e_{2}\right)$, and the observed state is $s$. 
More formally, a group contract first involves the (possibly random) choice of withingroup Pareto weights, $\operatorname{Pr}(\mu)$, then the choice (also possibly random) of efforts, $\operatorname{Pr}(\mathbf{e} \mid \mu)$, and finally aggregate consumption conditional on the within-group Pareto weights, outputs (following a random production function $\operatorname{Pr}(\mathbf{q} \mid \mathbf{e}, k, s)$ ), efforts, and the observed state $s$, $\operatorname{Pr}\left(c_{a} \mid \mu, \mathbf{q}, \mathbf{e}, s\right)$. The collusion-proof condition implies that when efforts $\mathbf{e}$ and consumption levels $\mathbf{c}$ are recommended, it must be the case that, for a pair of weights $\mu_{1}$ and $\mu_{2}$,

$$
\begin{aligned}
\sum_{c_{a}, \mathbf{q}, s} \operatorname{Pr}\left(c_{a} \mid \mathbf{e}, \mathbf{q}, s\right) \operatorname{Pr}(\mathbf{q} \mid \mathbf{e}, k, s) \sum_{i} \mu_{i} u\left(c_{i}\right) \geq \\
\sum_{c_{a}, \mathbf{q}, s} \operatorname{Pr}\left(c_{a} \mid \mathbf{e}, \mathbf{q}, s\right) \operatorname{Pr}(\mathbf{q} \mid \overline{\mathbf{e}}, k, s) \sum_{i} \mu_{i} u\left(\bar{c}_{i}, \bar{e}_{i}\right)
\end{aligned}
$$

for any $\overline{\mathbf{e}}$ and any $\mathbf{c}$ and $\overline{\mathbf{c}}$, such that $c_{1}+c_{2}=\overline{c_{1}}+\overline{c_{2}}=c_{a}$, where $c_{a}$ is the aggregate consumption within the group. When the utility function is separable, i.e., $u\left(c_{i}, e_{i}\right)=\widetilde{u}\left(c_{i}\right)-$ $v\left(e_{i}\right)$, this condition implies that c solves the following within-group Pareto problem:

$$
\max _{\mathbf{c}} \sum_{i} \mu_{i} \tilde{u}\left(c_{i}\right)
$$

subject to

$$
\sum_{i} c_{i}=c_{a}
$$

Henceforth, we assume that the utility function is separable, so the problem above is always satisfied in groups. In effect, we can write $\mathbf{c}$ as a function of $c_{a}$ and $\mu \equiv\left(\mu_{1}, \mu_{2}\right)$, i.e., $\mathbf{c}\left(c_{a}, \mu\right)$.

For notational purposes, we now write a group contract as a joint probability $\pi^{g}\left(c_{a}, \mu, \mathbf{q}, \mathbf{e}, s\right)=$ $\operatorname{Pr}(\mu) \operatorname{Pr}(\mathbf{e} \mid \mu) \operatorname{Pr}(\mathbf{q} \mid \mathbf{e}, k, s) \operatorname{Pr}\left(c_{a} \mid \mathbf{q}, \mathbf{e}, s, \mu\right) \operatorname{Pr}\left(A_{s}\right)$. Hence, this contract is the probability that a group of agents will obtain aggregate consumption $c_{a}$, be assigned within-group Pareto weights $\mu=\left(\mu_{1}, \mu_{2}\right)$, produce outputs $\mathbf{q}=\left(q_{1}, q_{2}\right)$, undertake the recommended efforts $\mathbf{e}=\left(e_{1}, e_{2}\right)$, and realize the observed state $s$.

The collusion-proof condition (16) can now be rewritten in the form of the following group incentive constraints for each $\mu, \mathbf{e}, \widetilde{\mathbf{e}}$ :

$$
\begin{aligned}
& \sum_{c_{a}, \mathbf{q}, s} \pi^{g}\left(c_{a}, \mu, \mathbf{q}, \mathbf{e}, s\right) \sum_{i} \mu_{i} u\left(c_{i}\left(c_{a}, \mu\right), \mathbf{e}\right) \geq \\
& \sum_{c_{a}, \mathbf{q}, s} \pi^{g}\left(c_{a}, \mu, \mathbf{q}, \mathbf{e}, s\right) \frac{\operatorname{Pr}(\mathbf{q} \mid \widetilde{\mathbf{e}}, k, s)}{\operatorname{Pr}(\mathbf{q} \mid \mathbf{e}, k, s)} \sum_{i} \mu_{i} u\left(c_{i}\left(c_{a}, \mu\right), \widetilde{\mathbf{e}}\right) .
\end{aligned}
$$


Note that in (16), the within-group Pareto weights that are present in the risk sharing condition (17) must be the same as those in the group incentive constraint (19). Additionally, note that in the group regime, there is a unique incentive constraint, which reflects that the decisions are made jointly.

As a probability measure, a contract $\pi^{g}\left(c_{a}, \mu, \mathbf{q}, \mathbf{e}, s\right)$ must satisfy the following probability constraint:

$$
\sum_{c_{a}, \mu, \mathbf{q}, \mathbf{e}, s} \pi^{g}\left(c_{a}, \mu, \mathbf{q}, \mathbf{e}, s\right)=1, \pi^{g}\left(c_{a}, \mu, \mathbf{q}, \mathbf{e}, s\right) \geq 0, \quad \forall\left(c_{a}, \mu, \mathbf{q}, \mathbf{e}, s\right) .
$$

Again, $\pi^{g}\left(c_{a}, \mu, \mathbf{q}, \mathbf{e}, s\right)$ must be subject to mother nature constraints that guarantee that realized outputs are consistent with the productive technology:

$$
\sum_{c_{a}} \pi^{g}\left(c_{a}, \bar{\mu}, \overline{\mathbf{q}}, \overline{\mathbf{e}}, \bar{s}\right)=\operatorname{Pr}(\overline{\mathbf{q}} \mid \overline{\mathbf{e}}, k, \bar{s}) \sum_{c_{a}, \mathbf{q}} \pi^{g}\left(c_{a}, \bar{\mu}, \mathbf{q}, \overline{\mathbf{e}}, \bar{s}\right), \forall(\bar{\mu}, \overline{\mathbf{q}}, \overline{\mathbf{e}}, \bar{s})
$$

The participation constraints for the group regime are as follows:

$$
\sum_{c_{a}, \mu, \mathbf{q}, \mathbf{e}, s} \pi^{g}\left(c_{a}, \mathbf{q}, \mathbf{e}, s\right) u\left(c_{i}\left(c_{a}, \mu\right), \mathbf{e}\right) \geq \bar{u}_{i}, \quad i=1,2
$$

Finally, the distribution of effort must be independent of the information set $A_{s}$. Thus:

$$
\sum_{c_{a}, \mathbf{q}} \pi^{g}\left(c_{a}, \bar{\mu}, \mathbf{q}, \overline{\mathbf{e}}, \bar{s}\right)=\operatorname{Pr}\left(A_{\bar{s}}\right) \sum_{c_{a}, \mathbf{q}, s} \pi^{g}\left(c_{a}, \bar{\mu}, \mathbf{q}, \overline{\mathbf{e}}, s\right), \forall(\bar{s}, \overline{\mathbf{e}}, \bar{\mu})
$$

A group firm is an optimal contract that solves the following surplus maximization problem:

\section{Program 2.}

$$
\max _{\pi^{g}} \sum_{c_{a}, \mu, \mathbf{q}, \mathbf{e}, s} \pi^{g}\left(c_{a}, \mu, \mathbf{q}, \mathbf{e}, s\right)\left(q_{1}+q_{2}-c_{a}\right)
$$

subject to constraints $19,, 20), 21,22$, and 23 . 


\subsection{Comparing Regimes: The Roles of Information, Wealth, and Inequality}

In this section, we present theoretical results comparing the surplus generated by groups versus relative performance organizations. In principle there might be costs related to adopting one regime or the other $4^{4}$ On the one hand, relative performance requires preventing side payments and collusion among agents. On the other hand, groups require mutual observability of efforts. Imposing these conditions might be costly. However, our goal is to compare cooperative versus competitive incentive schemes assuming that they are available, and we are agnostic about these costs.

We consider a symmetric case, in which the promised utility levels of both workers are identical, i.e., $\bar{u}_{1}=\bar{u}_{2}$. In this case, we analytically demonstrate that for any relative performance contract, there exists a group contract that generates a higher surplus when the common shocks are perfectly observed. In other words, the optimal organizational regime depends on the informational regime $z$. This argument is formally presented in Proposition 1 below.

Intuitively, the relative performance regime tends to dominate (generate a larger surplus) when the correlation of outputs is high, and vice versa. However, when it is possible to observe the common shock $\omega$ perfectly, the outputs are (ex post) uncorrelated across agents conditional on $\omega$, as in (3). Therefore, similar to Ramakrishnan and Thakor (1991) and Itoh (1993), this study notes that the group regime will dominate when the local shocks are perfectly observed because the (ex-post) correlation of outputs is zero in this case. A key assumption is that the correlation of outputs results from local shocks only (Assumption 1).

Proposition 1. With additively separable utility and perfect observability of common shocks, for any feasible surplus maximizing relative performance contract with $\bar{u}_{i}=\bar{u}$ for all $i$, there exists a feasible group contract with the same utility level for all agents that generates a weakly larger surplus. Further, when such relative performance contract has binding incentive constraints, a feasible group contract generates a strictly higher surplus, with the same utility

\footnotetext{
4 Madeira and Townsend (2008), for instance, assume that there is a cost related to adopting relative performance.
} 
promise for all agents.

A proof of Proposition 11 is provided in the appendix. A simple intuition for the twoagent case is the following. Suppose there is full information about $\omega$. For given efforts and $\omega$, an optimal relative performance contract will simply determine, for each individual, an amount of consumption conditional on his own output (regardless of the output of the other, since outputs are independent given $\omega)$. A group with equal Pareto weights, would be able to satisfy the incentive constraint with the following scheme. When outputs are equal among agents, they receive the same consumption as in relative performance. When outputs are different among individuals, both receive a certainty equivalent of a lottery that give each of the relative performance consumptions with probability 0.55 . This step would save resources, given risk aversion, thus increasing the total surplus ${ }^{6}$. Intuitively the advantage of groups comes from the capacity of providing risk sharing in cases where outputs are different. This argument easily extends up to the case with more than two agents.

Proposition 2 below considers another extreme case, in which relative performance always dominates, regardless of the observability of common shocks. This case applies when idiosyncratic shocks are absent and arbitrarily high punishment is allowed. The first condition states that an individual productive technology $f(q \mid e, k, \omega)$ has no idiosyncratic shocks if, for any $(q, e, k, \omega)$ either $f(q \mid e, k, \omega)=0$ or $f(q \mid e, k, \omega)=1$. Thus, idiosyncratic shocks will be absent if the distribution of outputs conditional on the common shock is always degenerate. The second condition is that $\inf _{c_{i}} u\left(c_{i}, e_{i}\right)$ is sufficiently negative for any $e_{i}$.

Proposition 2. Suppose that $f(q \mid e, k, \omega)$ has no idiosyncratic shocks, and that an arbitrarily high punishment is allowed, i.e., $\inf _{c_{i}} u\left(c_{i}, e_{i}\right)$ is sufficiently negative for any $e_{i}$. Then, for any optimal group contract with a binding incentive constraint and $\bar{u}_{i}=\bar{u}$ for all $i$, there exists a feasible relative performance contract with the same utility level for all agents that generates a strictly larger surplus.

\footnotetext{
${ }^{5}$ Under relative performance, one agent would consume $c_{1}$ and the other would consume $c_{2}$. The lottery mentioned gives each of these outcomes with probability 0.5

6 Note that this consumption scheme would increase the payoff of lower effort for a given individual acting independently (as in relative performance), since a contingency in which he is the only one with the lower output would now generate higher consumption. So this scheme would not be feasible under relative performance
} 
A formal proof of Proposition 2 is provided in the appendix. The intuition behind this result is straightforward. With no idiosyncratic shocks, different outputs can only happen when efforts are different. A very strong punishment when outputs are different would easily motivate them to make the recommended level of effort, so that different output levels would not be observed and full insurance would be possible (even if the effort recommended is not the lowest one). Again, this result is valid regardless of the number of agents in each organization.

This proposition implies that a relative performance regime dominates a group regime, regardless of the information structure, as long as idiosyncratic shocks are absent and punishment can be sufficiently harsh. This result emphasizes the role of idiosyncratic shocks in group regimes. Note that the first-best optimal allocation can be achieved by either a relative performance regime or a group regime if the common shocks are perfectly observed.

\section{General Equilibrium with Endogenous Organizational and Informational Regimes}

This section presents a general equilibrium model with endogenous organizational and informational regimes. To save some space, the welfare theorems and the existence theorem are omitted but they are available in our working paper version Kilenthong and Madeira (2013). See also Prescott and Townsend (2006) for a similar general equilibrium model with endogenous organizational regimes.

\subsection{Competitive Equilibrium}

Let $B$ be a finite set of all potential firms (optimal contracts with different organizational regimes, informational regimes, capital inputs, and promised utility levels). A typical firm $b$ specifies an organizational form (either relative performance or group evaluation), informational regime $z(b)$, capital input $k(b)$, and the promised utility level $\bar{u}(b, j)$ for a worker in the $j^{\text {th }}$ position. In addition, each firm $b$ is associated with an expected surplus $S(b)$. With a continuum of firms, the expected surplus of a firm is equal to the average surplus of firms 
of the same type.

Denote the probability of an agent of type $i$ working in position $j$ in firm $b$ by $x^{i}(b, j)$. With a continuum of agents, $x^{i}(b, j)$ can also be interpreted as the fraction of agents assigned to a bundle $(b, j)$. With all choice objects gridded up as an approximation, the commodity space $L \subset \mathbb{R}^{n}$ is assumed to be a finite-dimensional space in which $n$ is the number of possible bundles $(b, j)$. Let $\mathbf{x}^{i}$ denote an $n$ dimensional vector or a lottery, each element of which is the probability of being assigned to a given bundle $(b, j), x^{i}(b, j)$.

As a probability measure, a lottery $\mathbf{x}^{i}$ must satisfy the following probability constraint:

$$
\sum_{(b, j)} x^{i}(b, j)=1 .
$$

The consumption possibility set of an agent of type $i$ is then defined by the following:

$$
X^{i}=\left\{\mathbf{x}^{i} \geq 0: \sum_{(b, j)} x^{i}(b, j)=1\right\}
$$

The linearity of the constraints ensures the convexity of the consumption possibility set $X^{i}$.

The preferences of an agent of type $i$ over $X^{i}$ are defined as follows:

$$
\sum_{(b, j)} x^{i}(b, j) \bar{u}(b, j)
$$

Let $P(b, j)$ be the price of a bundle $(b, j)$ or the price of the $j^{\text {th }}$ position in firm $b$. Note that the price of the capital good is 1 as it is the numeraire good. Each agent is infinitesimally small relative to the entire economy and takes all prices as given. The intermediaries introduced below are assumed to act competitively.

Workers: Each agent type $i$, taking prices $P(b, j)$ as given, chooses $\mathbf{x}^{i}$ to maximize his utility:

$$
\max _{\mathbf{x}^{i}} \sum_{(b, j)} x^{i}(b, j) \bar{u}(b, j)
$$

subject to the probability constraint

$$
\sum_{(b, j)} x^{i}(b, j)=1
$$

and the budget constraint

$$
\sum_{(b, j)} P(b, j) x^{i}(b, j) \geq \kappa^{i}
$$


The budget constraint 30 states that the agent sells her full endowment $\kappa^{i}$ and uses the proceeds to buy lotteries $\mathbf{x}^{i}$.

Intermediaries: The primary role of an intermediary is to create firms by assigning/matching workers to firms and generating information about local underlying states when necessary. With constant returns to scale, the profit of an intermediary is zero, and the number of intermediaries becomes irrelevant. Therefore, without a loss of generality, we assume that there is one representative intermediary who takes prices as given.

More formally, the intermediary creates $y(b) \in \mathbb{R}_{+}$units of firms of type $b$, and must fills both positions within the firm. Note that the intermediary can issue any non-negative number of firms/positions; that is, the number of firms issued need not be between zero and one and is not a lottery. Let $\mathbf{y} \in L$ be the vector of the number of firms issued, each element of which is the number of firms of each type $b$.

By creating a firm of type $b$, the intermediary must deliver the promised capital $k(b)$, must pay the information cost of $C(b)$, and must deliver potentially state-contingent transfers conditional on outputs, consumption, and the observed state, i.e., $T(b \mid \mathbf{q}, \mathbf{c}, s)$. Using the law of large numbers, the average transfers (per unit of firm) over all firms of type $b$ is $\sum_{\mathbf{q}, \mathbf{c}, s} T(b \mid \mathbf{q}, \mathbf{c}, s)=-S(b)$. Therefore, the intermediary must hold (buy/sell) $-y(b) S(b)$ units of future contracts at the price $P_{S}$.

The objective of the intermediary is to maximize its profit by choosing the number of firms $\mathbf{y}$, taking prices $P(b, j)$ and $P_{S}$ as given:

$$
\max _{\mathbf{y}} \sum_{b} y(b)\left[\sum_{j} P(b, j)-k(b)-C(b)+P_{S} S(b)\right] .
$$

As in Prescott and Townsend (2006), the existence of an optimum in the intermediary's problem requires that for any bundle $(b, j)$,

$$
\sum_{j} P(b, j) \leq k(b)+C(b)-P_{S} S(b)
$$

which holds with equality if $y(b)>0$. See for a similar. Here $\sum_{j} P(b, j)$ is the revenue from the sale of memberships in firm $b$, and is the cost of creating firm $b$. This condition is in fact a necessary and sufficient condition for the saddle-point problem (31). 
Market Clearing: The market-clearing condition for capital inputs is as follows:

$$
\sum_{b} y(b)[k(b)+C(b)]=\sum_{i} \alpha^{i} \kappa^{i}
$$

The market-clearing conditions for lotteries are the following:

$$
\sum_{i} \alpha^{i} x^{i}(b, j)=y(b), \forall b ; j=1,2 .
$$

In addition, the market for future contracts clears, i.e.,

$$
\sum_{b} y(b) S(b) \geq 0
$$

Definition 1. A competitive equilibrium is a specification of allocations $(\mathbf{x}, \mathbf{y})$, and the price of a position $j$ in firm $b, P(b, j)$, and the unit price of the future contract, $P_{S}$, such that

(i) for each $i, \mathbf{x}^{i} \in X^{i}$ solves (28), subject to (30), taking prices $P(b, j)$ as given;

(ii) for the intermediary, $\mathbf{y} \in L$ solves (31), taking prices $P(b, j)$ and $P_{S}$ as given; and

(iii) the markets for capital inputs, lotteries, and future contracts clear, i.e., (33), (34), and (35) hold.

As in Prescott and Townsend (2006), the economy here is a well defined convex economy. Therefore, the first and second welfare theorems hold, and a competitive equilibrium exists as in their model. For the sake of brevity, all theorems and their proofs are omitted. Readers can see Kilenthong and Madeira (2013) and Prescott and Townsend (2006) for more details.

\subsection{Pareto Optimal Allocations}

We characterize the constrained optimum using the following Pareto program. Let $\lambda^{i} \geq 0$ be the ex-ante (before organization assignment) Pareto weight on an agent type 7 . Without a loss of generality, we can normalize the weights such that $\sum_{i} \lambda^{i}=1$. A constrained Pareto optimal allocation solves the following Pareto program.

\footnotetext{
${ }^{7}$ Note that $\lambda^{i}$ represents ex-ante Pareto Weights, while $\mu^{i}$ represents ex-post inside-group Pareto weights. As it is shown in Prescott and Townsend (2002), they are not necessarily the same. For instance, it is possible that agents with different Pareto weights are assigned to different groups, and in each of these groups they have equal Pareto weights.
} 


\section{Program 3.}

$$
\max _{\left(\mathbf{x}^{i}, \mathbf{y}\right)} \sum_{i} \lambda^{i} \alpha^{i} \sum_{(b, j)} x^{i}(b, j) \bar{u}(b, j)
$$

subject to

$$
\begin{aligned}
\sum_{(b, j)} x^{i}(b, j) & =1, \forall i, \\
\sum_{i} \alpha^{i} x^{i}(b, j) & =y(b), \forall b ; j=1,2, \\
\sum_{b} y(b)[k(b)+C(b)] & =\sum_{i} \alpha^{i} \kappa^{i}, \\
\sum_{b} y(b) S(b) & =0 .
\end{aligned}
$$

Note that the Pareto program includes all of the incentive constraints, which are embedded in the grids of potential firms, through the surplus of each firm $S(b)$.

\subsection{Numerical Examples}

This section presents numerical examples of competitive equilibria, We solved the model for a large set of specifications, including different levels of risk aversion, wealth, inequality and cost of information. Our results show that the relationship between availability of information and cooperation is robust to a large set of specifications. They also bring insights into how wealth, inequality, effort, and information interact to generate general equilibrium effects.

The numerical examples are based on the following model economy. There are two possible local underlying states, i.e., $\Omega=\{1,2\}$, each of which occurs with an equal probability, i.e., $\operatorname{Pr}(\omega=1)=\operatorname{Pr}(\omega=2)=0.5$. Therefore, there are only two possible informational regimes, $F_{\underline{z}}=\{\{1,2\}\}$ (no information) and $F_{\bar{z}}=\{\{1\},\{2\}\}$ (full information).

Each agent derives her utility from the following utility function

$$
u(c, e)=\frac{c^{1-\rho}}{1-\rho}-\frac{e^{1-\rho}}{1-\rho},
$$

\footnotetext{
${ }^{8}$ Technically, we solved Program 3, with 900 pairs of utility promises for each regime (groups with information, groups without information, relative performance with information, and relative performance without information). Wealth inequality is measured by Pareto weights $\lambda$ in all of the examples.
} 
where $c, e$ and $\rho$ denote consumption, effort $9^{9}$ and the relative risk aversion coefficient, respectively. Effort $e$ can take only two values: $e^{l}=2.25$ (low effort) and $e^{h}=6.25$ (high effort). The relative risk aversion coefficient $\rho$ can take on any positive number.

Output can take only two values: $q^{l}=2$ (low output) and $q^{h}=20$ (high output). The production technology is assumed to be linearly additive in capital as follows.

$$
f(q+k \mid e, \omega, k)=\tilde{f}(q \mid e, \omega)
$$

In our benchmark technology, $\tilde{f}(q \mid e, \omega)$ is defined according to the probability distribution in Table 1. We chose a specification that makes the value of information for incentives clear. There is one state of the world in which effort is crucial, and another state in which effort is irrelevant. Knowledge about the state is very useful to determine if outputs are informative about efforts. In this benchmark specification, output correlation is 0.32 when both individuals make the same effort (either high or low).

Table 1: Distribution of output conditional on a local state, $f(q \mid e, \omega)$, for the benchmark case.

\begin{tabular}{cccccc}
\hline \hline & \multicolumn{2}{c}{$\omega=1$} & & \multicolumn{2}{c}{$\omega=2$} \\
\cline { 2 - 3 } \cline { 5 - 6 } & $e^{h}$ & $e^{l}$ & & $e^{h}$ & $e^{l}$ \\
\hline$\tilde{f}\left(q^{h} \mid e, \omega\right)$ & 0.99 & 0.01 & & 0.50 & 0.50 \\
$\tilde{f}\left(q^{l} \mid e, \omega\right)$ & 0.01 & 0.99 & & 0.50 & 0.50 \\
\hline
\end{tabular}

There are two types of agents, i.e., $i=1,2$. Both types of agents have the same mass, i.e., $\alpha^{1}=\alpha^{2}=0.5$. The key heterogeneity between agents lies in initial capital endowment $\kappa^{i}$.

In all specifications studied, all firms invest in information when its cost is zero, since better information leads to more efficient contracts. This is true for all levels of risk aversion and wealth inequality, as shown in Figure $1 \mathrm{a}$ and $1 \mathrm{~b}$, which depict the probability of

\footnotetext{
${ }^{9}$ Making the marginal utility of effort depend on $\rho$ as above is convenient to study jointly different risk aversions since it makes effort and consumption comparable, which brings the regime areas to similar wealth ranges. Changes in the values of $q^{h}, q^{l}, e^{h}$ and $e^{l}$ have no impact in the general profile of solutions, although they change the wealth range where regimes are found.
} 
acquisition of information as a function of it's cost, for different risk aversions and inequality levels. The figures show that the fraction of firms purchasing information is decreasing with the information $\cos 10$

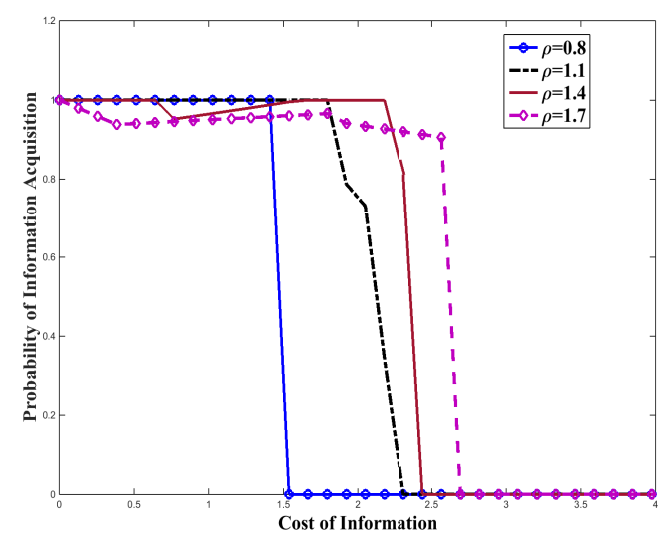

(a)

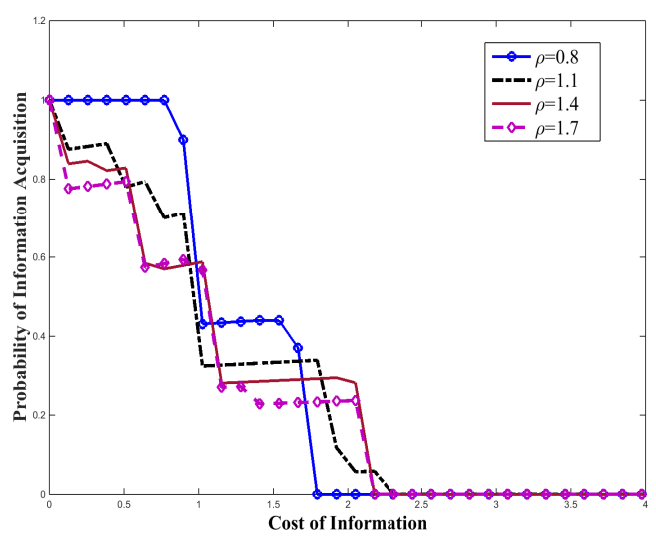

(b)

Figure 1: (a) Fraction of firms that invest in information when $\lambda=(0.5,0.5)$, aggregate wealth $\sum_{i} \alpha^{i} \kappa^{i}=-17$. (b) Fraction of firms that invest in information when $\lambda=(0.7,0.3)$, aggregate wealth $\sum_{i} \alpha^{i} \kappa^{i}=-17$.

For all specification: ${ }^{11}$, only group firms are active in equilibrium when the cost of information is zero. This result is true for both equal-wealth and unequal-wealth economies, as shown in Figure $2 \mathrm{a}$ and $2 \mathrm{~b}$, respectively. As the cost of information increases, relative performance regime starts to emerge. The probability of groups is normally decreasing with the cost of information.

An important result that is found in all specifications studied, is that only group firms acquire information about $\omega$ in equilibrium. This does not mean that this information is not beneficial to the relative performance regime. In fact, information about the states

\footnotetext{
${ }^{10}$ There are some slightly upward sloping areas in some of these lines, possibly related to the fact that we have a finite (although large) grid.

${ }^{11}$ We performed a larger set of computation than those presented in this session. we computed the general equilibrium for a grid of 20 values of $\lambda, 40$ values of wealth, 5 levels of risk aversion and 4 specifications of the production function. In all of these specifications, when the cost of information is zero there is information acquisition with probability one, and group firms are the adopters whenever information is acquired.
} 
allow more state contingent contracts, which generally improves welfare. However, relative performance firms never acquire information in the computational exercises. In equilibrium, only three regimes exist: groups with information, groups without information, and relative performance without information (hereafter simply called relative performance). This is related to the fact that, in our formulation, acquiring information is equivalent to acquiring full information about common shocks 12

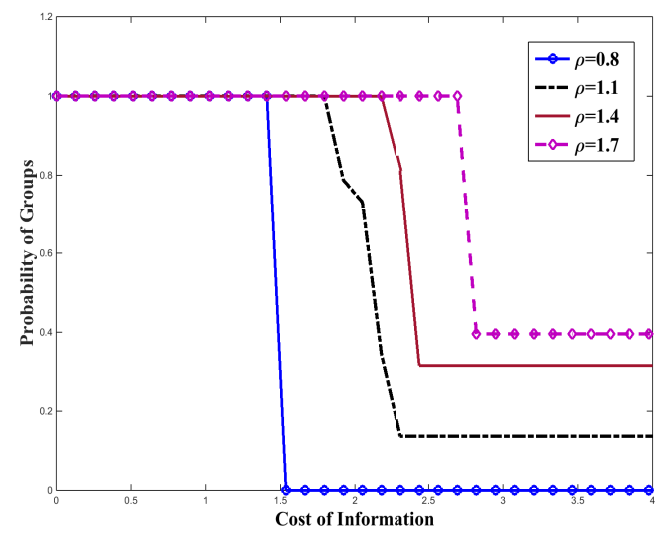

(a)

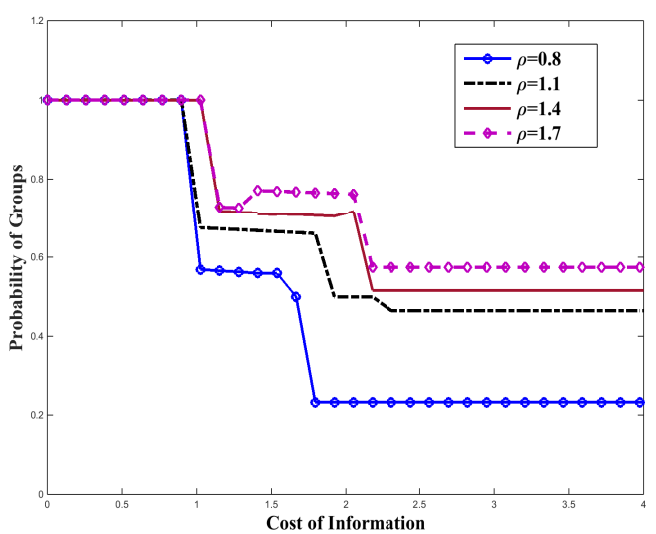

(b)

Figure 2: (a) Fraction of firms that use group contracts when $\lambda=(0.5,0.5)$, aggregate wealth $\sum_{i} \alpha^{i} \kappa^{i}=-17$. (b) Fraction of firms that use group contracts when $\lambda=(0.7,0.3)$, aggregate wealth $\sum_{i} \alpha^{i} \kappa^{i}=-17$.

As shown in Figure 3, small changes in the cost of information can reshape the organization structure completely, both in terms of regime and matching of agent types. General equilibrium effects are crucial to determine how these dramatic changes occur. In the example presented in Figure 3a, only group firms with information are active when the information cost is sufficiently low. As the cost of information approaches a certain value (slightly smaller than 1) there is a sudden transition to another type of equilibrium in which the three types of firms, relative performance, group without information and group with information, coexist.

\footnotetext{
${ }^{12}$ This result may not be true in general, especially when investment in partial information about common shocks is possible. Partial information that bring small gains should be purchased by relative performance organizations if its cost is sufficiently low. However, in a region where relative performance dominates, if this gain is sufficiently small, relative performance will be dominant, and, in this case, not invest in information.
} 
After this point, for a certain range of the cost of information, group firms with information employs just one type of agents (type one, with high wealth), and relative performance firms employ the other type of agents (type 2, with lower wealth), while group firms without information employs both types of agents. This matching pattern is presented in Figure 4 a. Given this distribution of types, general equilibrium constraints require that the mass of relative performance firms equals the mass of group firms. As the cost approaches another critic value, roughly close to 1.5 , another dramatic reorganization occurs. Groups with information disappear, and the market is split between relative performance firms and group firms without information. Importantly, now all firms, both relative performance and group without information, employ same type of workers (group firms absorb wealthy agents and relative performance firms take poor agents). That is, the matching structure completely changes again. Note that the regime profile is similar for a higher risk aversion $(\rho=1.4)$, as shown in Figure $3 \mathrm{~b}$,

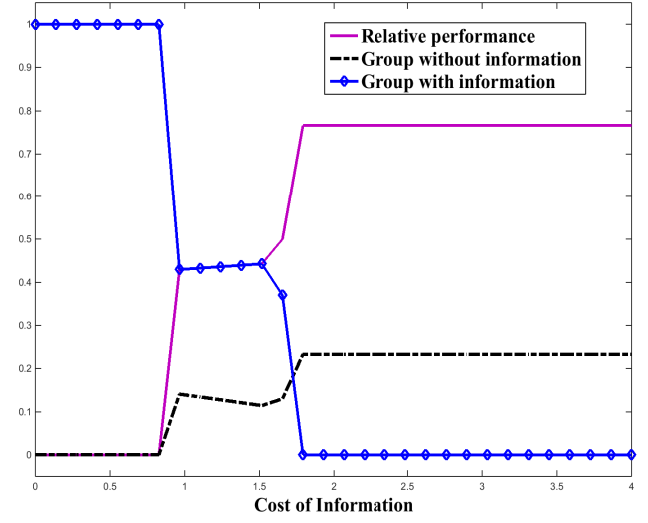

(a)

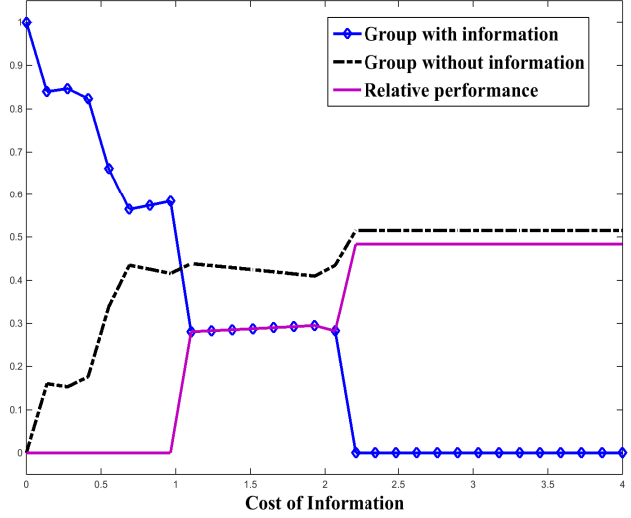

(b)

Figure 3: (a) Fraction of firms in relative performance, group without information, and group without information regimes when $\lambda=(0.7,0.3), \rho=0.8$ and aggregate wealth $\sum_{i} \alpha^{i} \kappa^{i}=-17$. (b) Fraction of firms in relative performance, group without information, and group without information regimes when $\lambda=(0.7,0.3), \rho=1.4$ and aggregate wealth $\sum_{i} \alpha^{i} \kappa^{i}=-17$.

In order to understand the distribution of types across organizations, it is important to 


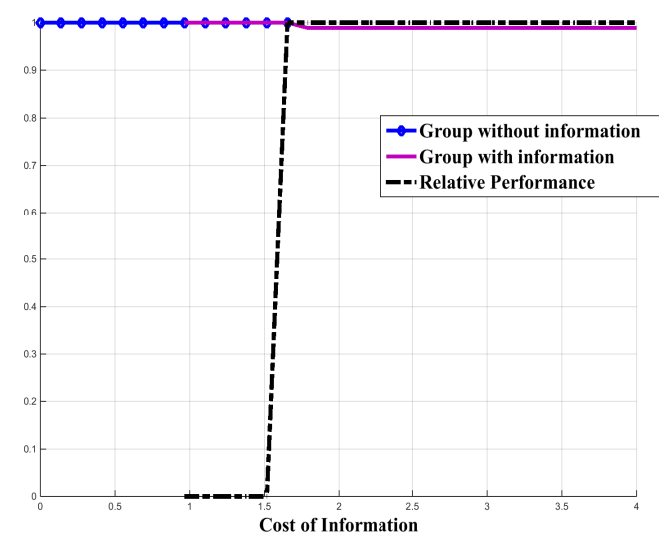

(a)

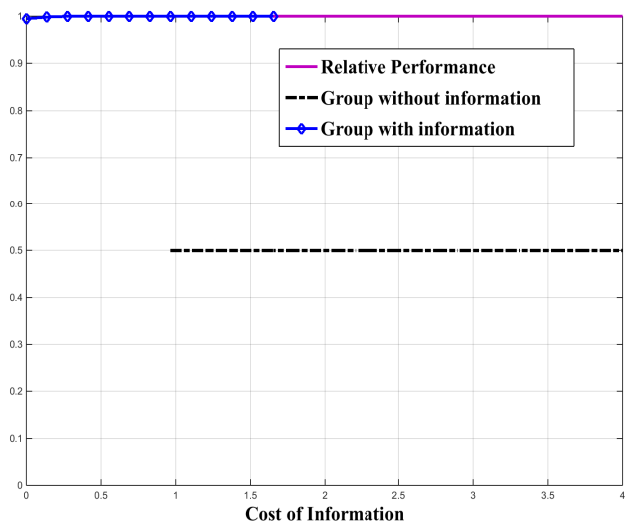

(b)

Figure 4: (a) Probability of having the same type of agents in a firm conditional each regime when $\lambda=(0.7,0.3), \rho=0.8$ and aggregate wealth $\sum_{i} \alpha^{i} \kappa^{i}=-17$. (b) Probability of having high effort in a firm (Probability will be one only if both of them exert high effort) conditional each regime when $\lambda=(0.7,0.3), \rho=0.8$ and aggregate wealth $\sum_{i} \alpha^{i} \kappa^{i}=-17$.

consider the relationship between the efforts recommended to agents and the optimal organizational assignment. Groups without information are particularly efficient to manage agents who make different efforts. In all the numerical exercises performed, groups without information are chosen in organizations where effort is unequal across agents. Figure $4 \mathrm{~b}$ shows that, in the example just mentioned, groups without information have one agent exerting high effort while the other exerts low effort. On the other hand, all agents in the other types of firms exert high effort. Given that the optimal levels of effort are different within the group without information firms, it can be convenient to employ different types of agents. This helps to explain why groups without information employ different types of agents while others employ the same types. This profile also shows the benefit of the additional information on enforcing high-effort contracts. As the information becomes sufficiently cheap (below 1), agents move from group without information firms, where effort is sometimes low, to group with information firms, where efforts are always high.

Aggregate wealth also plays an important role on information acquisition and organizational designs. This is shown in Figures $5 a$ and $6 a$, where we examine the organizational 
profile across different levels of aggregate wealth for a particular level of the information $\operatorname{cost}{ }^{13}$. With extremely low aggregate wealth, there is no information acquisition. This happens because information acquisition requires capital, which can also be used to produce goods for consumption. With extremely low wealth, it is too costly to spend the limited resources for information investment. This is true for both equal-wealth and unequal-wealth economies. As aggregate wealth grows, all firms start to acquire information. When the aggregate wealth is sufficiently large, firms start assign low effort to agents and information becomes less valuable. For extremely high wealth levels, both agents make low effort, so the relative performance and group regimes are equivalent, since none of the incentive constraints are binding. In this case there is full insurance. ${ }^{14}$ (see Figure $5 \mathrm{~b}$ and $6 \mathrm{~b}$ ).

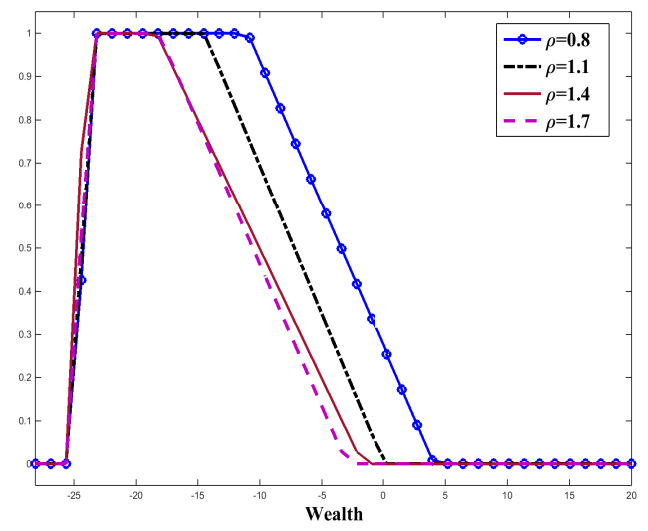

(a)

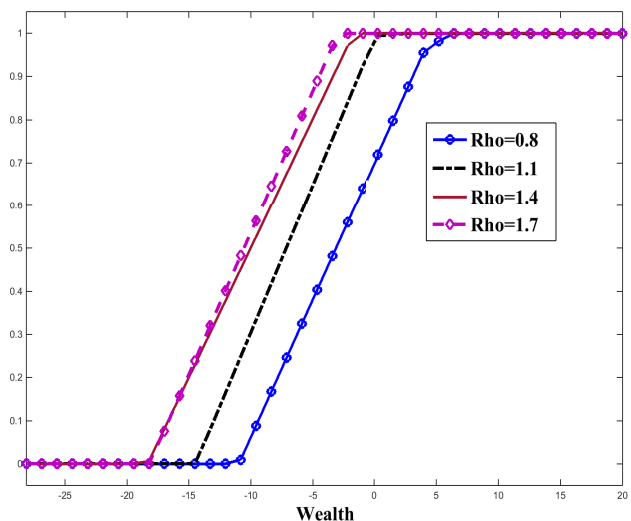

(b)

Figure 5: (a) Probability of information acquisition when $\lambda=(0.5,0.5)$, and cost of information $C=0.9$. (b) Probability that relative performance and group regimes are equivalent when $\lambda=(0.5,0.5)$, and cost of information $C=0.9$.

A complex profile of regimes given wealth emerges when there is inequality among agents. Figure 6a shows that the probability of information acquisition exhibits a double-peak pattern in the unequal-wealth economy when the relative risk aversion is high enough (above

\footnotetext{
${ }^{13}$ Note that wealth is sometimes negative, which can be interpreted as debt. Identical profiles with nonnegative wealth would be observed if we assumed there is a fixed cost in terms of capital for the firms to produce

${ }^{14}$ In other words, consumption will be constant, regardless of output realizations
} 


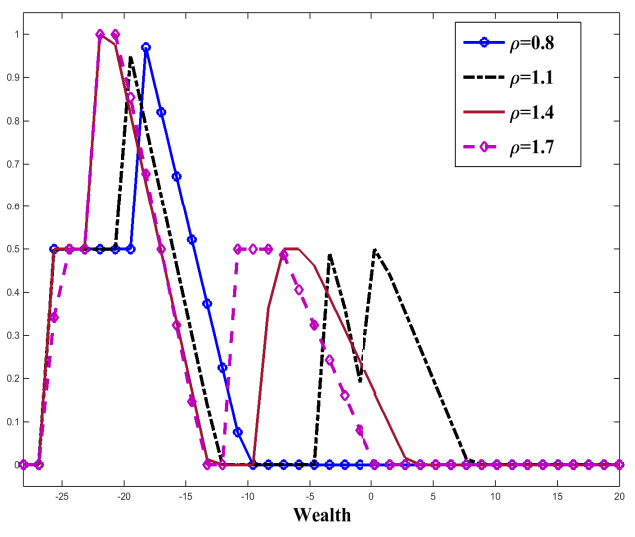

(a)

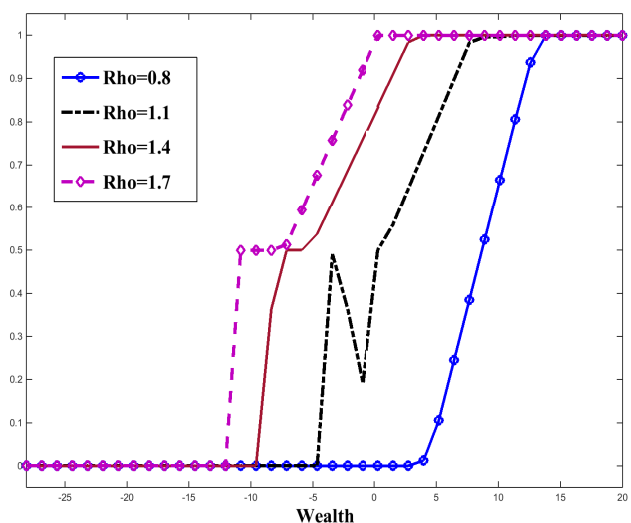

(b)

Figure 6: (a) Probability of information acquisition when $\lambda=(0.7,0.3)$ and cost of information $C=0.9$. (b) Probability that relative performance and group regimes are equivalent when $\lambda=(0.7,0.3)$, and cost of information $C=0.9$.

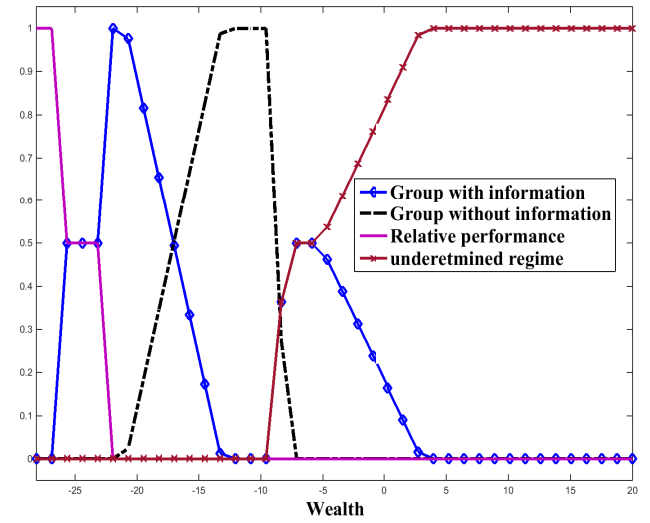

(a)

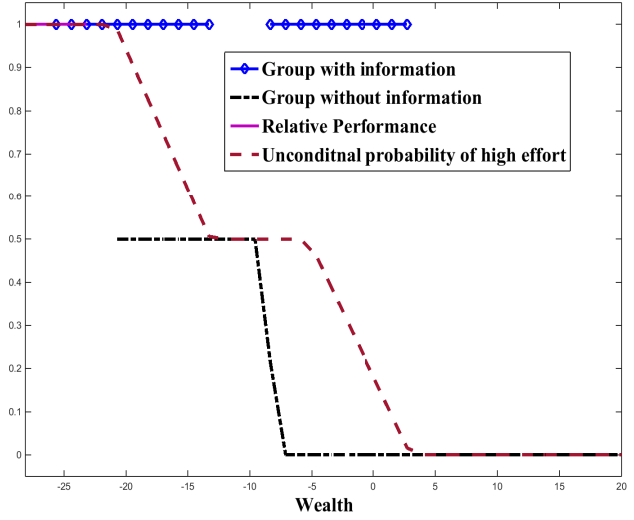

(b)

Figure 7: (a) Fraction of firms in relative performance, group without information, and group without information regimes when $\lambda=(0.7,0.3), \rho=1.4$ and cost of information $C=0.9$. (b) Probability of having high effort in a firm (Probability will be one only if both of them exert high effort) conditional each regime when $\lambda=(0.7,0.3), \rho=1.4$ and cost of information $C=0.9$. 
one). This is a consequence of general equilibrium effects. Let us consider the case with relative risk aversion $\rho=1.4$ and Pareto weights $\lambda=(0.7,0.3)$, described by Figure 7 . When wealth is extremely low, only the relative performance regime is active in equilibrium. As wealth increases, groups with information emerge and coexist with relative performance firms. Up to this point, all agents are assigned high effort. As wealth keeps increasing, some rich agents (type 1) will be assigned to group without information, where they exert low effort and match with poor agents (type 2). At some point, this type of firms completely dominates the entire economy. As this happens, group with information firms gradually disappear. In fact, the unconditional probability of high effort is decreasing from this point onward as shown in Figure 7b. As the optimal probability of high effort decreases, full insurance firms start to attract high Pareto weight members from groups without information. As a result, some of the poor agents (type 2) that are released from groups without information start matching with the same type to form groups with information, where both agents exert high effort. This generates a second peak in the fraction of groups with information. As wealth keeps increasing, eventually all type 1 individuals will be employed in a full insurance organization. Type 2 individuals start to move to this type of organization. Eventually, all agents will be in the full insurance organization with both agents making low effort.

Table 2: Distribution of output conditional on a local state, $f(q \mid e, \omega)$ for the "high correlation", "medium correlation", and "low correlation" cases.

\begin{tabular}{|c|c|c|c|c|c|c|c|c|c|c|c|c|}
\hline & \multicolumn{4}{|c|}{ High correlation $(0.36)$} & \multicolumn{4}{|c|}{ Medium correlation $(0.26)$} & \multicolumn{4}{|c|}{ Low correlation $(0.18)$} \\
\hline & \multicolumn{2}{|c|}{$\omega=1$} & \multicolumn{2}{|c|}{$\omega=2$} & \multicolumn{2}{|c|}{$\omega=1$} & \multicolumn{2}{|c|}{$\omega=2$} & \multicolumn{2}{|c|}{$\omega=1$} & \multicolumn{2}{|c|}{$\omega=2$} \\
\hline & $e^{h}$ & $e^{l}$ & $e^{h}$ & $e^{l}$ & $e^{h}$ & $e^{l}$ & $e^{h}$ & $e^{l}$ & $e^{h}$ & $e^{l}$ & $e^{h}$ & $e^{l}$ \\
\hline$\tilde{f}\left(q^{h} \mid e, \omega\right)$ & 0.9 & 0.1 & 0.35 & 0.65 & 0.85 & 0.15 & 0.4 & 0.6 & 0.8 & 0.2 & 0.45 & 0.55 \\
\hline$\tilde{f}\left(q^{l} \mid e, \omega\right)$ & 0.1 & 0.9 & 0.65 & 0.35 & 0.15 & 0.85 & 0.6 & 0.4 & 0.2 & 0.8 & 0.55 & 0.45 \\
\hline
\end{tabular}

Figure 8 shows how organization and information investment decisions respond to different levels of output correlation. The production technologies used for these exercises are presented in Table $2{ }^{15}$. The results show that the downward sloping profiles of the fraction

\footnotetext{
${ }^{15}$ In all of these production technologies, probabilities of high and low output conditional on effort (unconditional on $\omega$ ) are the same. The specifications depart from the benchmark case to make the effects of
} 


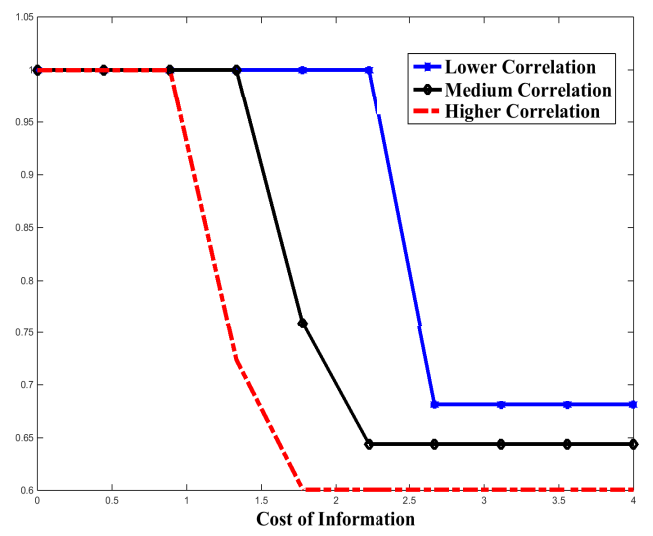

(a)

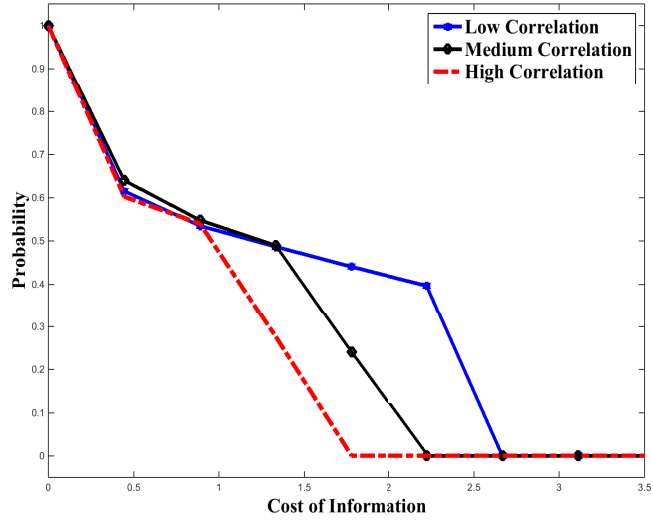

(b)

Figure 8: (a) Fraction of firms that use group contracts when $\lambda=(0.7,0.3), \rho=0.8$, aggregate wealth $\sum_{i} \alpha^{i} \kappa^{i}=-25.6$. (b) Fraction of firms that invest in information when $\lambda=(0.7,0.3), \rho=0.8$, aggregate wealth $\sum_{i} \alpha^{i} \kappa^{i}=-25.6$.

of groups and information acquisition are robust to changes in production technology. As in Ramakrishnan and Thakor (1991) and Itoh (1993), when the cost of information is high enough, so there is no information acquisition, high correlation diminishes the probability of groups.

A striking feature of Figure 8 is that higher correlation does not necessarily causes more information purchasing. Relative performance is used to deal with higher correlation and, in fact higher correlation diminishes the fraction of firms purchasing information. This result implies that the relationship between shocks, information and relative performance is subtle. Increases in correlation can, simultaneously, lead to more adoption of relative performance and less use of information.

\section{Conclusion}

This paper extends the multi-agent moral hazard model of Holmstrom and Milgrom (1990) in two respects: (i) we add the costly observability of common shocks, and (ii) we embed correlation clearer 
this structure in a Walrasian equilibrium model.

We present theoretical and numerical results showing that both relative-performance and cooperative/group regimes can be optimal, but information regarding common shocks yields greater benefits for cooperative regimes. These results suggest that the emergence of cooperative behaviors may be related to technological advances (e.g., lower costs of acquiring information). On the other hand, if information about common shocks is available, cooperation may be optimal even when outputs are highly correlated (contrast to Ramakrishnan and Thakor, 1991; Itoh, 1993). For a symmetric case in which individuals are ex ante identical, we proved that cooperation or group regimes prevail when common shocks are perfectly observable. In another polar case in which all shocks are common and punishment can be arbitrarily severe, relative performance regime always dominates, regardless of the information structure.

Our numerical exercises reveal that diverse organizational forms can coexist in equilibrium, but only groups obtain full information about common shocks. Both costs of information and the wealth of agents affect the set of organizations that are active in the economy. For a given cost of information, investment on information is more likely for intermediary levels of wealth. For these wealth levels, groups are likely to be dominant, while relative performance may appear for lower wealth levels. For a given level of wealth, if the cost of information is sufficiently low, only groups investing in information are observed. With higher costs of information, relative performance can be observed.

Examples show that general equilibrium effects can generate substantial reorganization of production in response to small changes in wealth or the cost of information, affecting both the set of organizational regimes operating and the assignment and matching patterns of heterogeneous agents given these regimes. A rich interplay among information, wealth, inequality and optimal effort levels is present in these transitions of regime configuration.

The current framework is compatible with a number of extensions. A dynamic version of the model could be informative with respect to co-movements and transitions and could also generate patterns of evolution in organizational forms, as agents learn about the environment and the production process. In addition, the model can be adapted to admit different sizes of organizations/firms, so that it can be used to analyze the optimal size of organizations 
and it's interplay with the availability of information regarding common shocks.

\section{References}

Ahlin, C. and R. Townsend (2007). Selection into and across credit contracts: theory and field research. Journal of Econometrics 136(2), 665-698.

Barlevy, G. and D. Neal (2012). Pay for Percentile. American Economic Review 102(5), $1805-31$.

Chiappori, P.-A., K. Samphantharak, S. Schulhofer-Wohl, and R. M. Townsend (2014). Heterogeneity and risk sharing in village economies. forthcoming in Quantitative Economics.

Deaton, A. (1992). Saving and income smoothing in cote d'ivoire. Journal of African Economies 1(1), 1-24.

Fafchamps, M. and F. Gubert (2007). The formation of risk sharing networks. Journal of Development Economics 83(2), 326-350.

Genicot, G. and D. Ray (2003). Group formation in risk-sharing arrangements. Review of Economic Studies 70(1), 87-113.

Ghatak, M. and T. Guinnane (1999). The economics of lending with joint liability theory and practice. Journal of development economics 60(1), 195-228.

Goldstein, M. (2000). Chop Time, No Friends: Risk and Intrahousehold Insurance in Southern Ghana.". Manuscript, London School of Economics.

Grimard, F. (1997). Household consumption smoothing through ethnic ties: Evidence from Cote dIvoire. Journal of Development Economics 53(2), 391-422.

Holmstrom, B. and P. Milgrom (1990). Regulating Trade Among Agents. Journal of Institutional and Theoretical Economics: JITE 146, 85-105.

Itoh, H. (1993). Coalitions, incentives, and risk sharing. Journal of Economic Theory 60(2), $410-427$. 
Jalan, J. and M. Ravallion (1999). Are the poor less well insured? Evidence on vulnerability to income risk in rural China. Journal of Development Economics 58(1), 61-81.

Kilenthong, W. T. and G. A. Madeira (2013). Observability and endogenous organizations. RIPED Working Paper.

Lazear, E. and S. Rosen (1981). Rank-order tournaments as optimum labor contracts. The Journal of Political Economy 89(5), 841-864.

Lazear, E. and K. Shaw (2007). Personnel economics: The economist's view of human resources. The Journal of Economic Perspectives 21 (4), 91-114.

Madeira, G. and R. Townsend (2008). Endogenous groups and dynamic selection in mechanism design. Journal of Economic Theory 142(1), 259-293.

Mueller, R., E. Prescott, and D. Sumner (2002). Hired hooves: Transactions in a south Indian village factor market. The Australian Journal of Agricultural and Resource Economics 46 , $233-255$.

Prescott, E. and R. Townsend (1984). General Competitive Analysis in an Economy with Private Information. International Economic Review 25(1), 1-20.

Prescott, E. and R. Townsend (2002). Collective organizations versus relative performance contracts: Inequality, risk sharing, and moral hazard. Journal of Economic Theory 103(2), $282-310$.

Prescott, E. and R. Townsend (2006). Firms as Clubs in Walrasian Markets with Private Information. Journal of Political Economy 114(4), 644-671.

Ramakrishnan, R. and A. Thakor (1991). Cooperation versus competition in agency. Journal of Law, Economics, and Organization 7(2), 248-283.

Ray, D. (2007). A game-theoretic perspective on coalition formation. Oxford University Press, USA.

Townsend, R. (1994). Risk and insurance in village india. Econometrica: Journal of the Econometric Society, 539-591. 
Townsend, R. and R. Mueller (1998). Mechanism design and village economies: From credit to tenancy to cropping groups. Review of Economic Dynamics 1(1), 119-172.

\section{A Proofs}

Proof of Proposition 1. This proof is written for the general case in which there is a finite number of firm members, $N \geq 2$. Consider a relative performance contract $\pi^{r}$ with $\bar{u}$. Feasibility requires that $\pi^{r}$ satisfies conditions (10), (11), (12), (13), (14). Perfect observability implies that one individual's output is not informative with regard to the outputs of other individuals in the firm. Hence, an individual's consumption $c_{i}$ will depend only on individual output $q_{i}$ and on the underlying state $\omega$. Given this information and the symmetry assumption, we can conclude that the optimal consumption for agent $i$ under a relative performance regime is $c_{i}^{r}=c\left(q_{i}, \omega\right)$.

We will now show that there is a feasible group contract $\pi^{g}$ that can generate a weakly larger surplus. Symmetry, i.e., $\bar{u}_{i}=\bar{u}$ for all $i$, implies that there is no loss of generality if we consider only a symmetric solution. That is, the within-group weights $\mu_{i}=\frac{1}{N}$ are symmetric16, where $N$ is the number of firm members. This symmetric solution also im-

plies symmetric consumption allocation, i.e., $c_{i}^{g}=\frac{c_{a}(\mathbf{q}, \omega)}{N}, \forall i$. For each relative performance contract $\pi^{r}(\mathbf{c}, \mathbf{q}, \mathbf{e}, s)$, we define a group contract $\pi^{g}\left(c_{a}, \mu, \mathbf{q}, \mathbf{e}, s\right)$ such that

$$
u\left(\frac{c_{a}(\mathbf{q}, \omega)}{N}\right)=\sum_{\ell=1}^{N} \frac{u\left(c\left(q_{\ell}, \omega\right)\right)}{N}
$$

and

$$
\pi^{g}\left(c_{a}, \mu, \mathbf{q}, \mathbf{e}, \omega\right)= \begin{cases}\pi^{r}(\mathbf{c}, \mathbf{q}, \mathbf{e}, \omega) & \text { when condition } 43 \text { holds and } \mu_{i}=\frac{1}{N} \\ 0 & \text { otherwise }\end{cases}
$$

The concavity of the utility function implies that the aggregate consumption specified in the group contract is no larger than the sum of the consumption allocations specified in the relative performance contract, i.e., $c_{a}(\mathbf{q}, \omega) \leq \sum_{i=1}^{N} c\left(q_{i}, \omega\right)$, which holds with equality if none of the incentive constraints is binding.

\footnotetext{
${ }^{16}$ Without a loss of generality, an optimal group contract with different weights must randomize across $\mu_{i}$, and it will do so only if advantageous. Therefore, the proof is valid.
} 
It is not difficult to show that the probability, mother nature, and consistency constraints, (10), (11), and (14), respectively, for the relative performance contract $\pi^{r}$, imply that the probability, mother nature, and consistency constraints, (20), (21), and (23), respectively, for the group contract $\pi^{g}$, hold. We now only need to show that the participation and incentive constraints, 22 and (19), respectively, for the group contract $\pi^{g}$ also hold under contract $\pi^{g}$. The separability of the utility function implies that there is no loss of generality if we suppress the effort in the utility function for the participation constraints.

The participation constraints, (12), in case of the relative performance contract $\pi^{r}$ can be rewritten as follows:

$$
\begin{aligned}
\bar{u}_{i} & \leq \sum_{\mathbf{c}, \mathbf{q}, \mathbf{e}, \omega} \pi^{r}(\mathbf{c}, \mathbf{q}, \mathbf{e}, \omega) u\left(c_{i}^{r}\right) \\
& =\sum_{\mathbf{c}, \mathbf{e}, \omega} \sum_{q_{-i}} \sum_{q_{i}} \pi^{r}\left(\mathbf{c}, q_{-i}, q_{i}, \mathbf{e}, \omega\right) u\left(c\left(q_{i}, \omega\right)\right)
\end{aligned}
$$

The symmetry assumption implies the following:

$$
\sum_{q_{-i}} \sum_{q_{i}} \pi^{r}\left(\mathbf{c}, q_{-i}, q_{i}, \mathbf{e}, \omega\right) u\left(c\left(q_{i}, \omega\right)\right)=\sum_{q_{-j}} \sum_{q_{j}} \pi^{r}\left(\mathbf{c}, q_{-j}, q_{j}, \mathbf{e}, \omega\right) u\left(c\left(q_{i}, \omega\right)\right), \forall i, j
$$

Thus, the following is implied:

$$
\begin{aligned}
\sum_{q_{-i}} \sum_{q_{i}} \pi^{r}\left(\mathbf{c}, q_{-i}, q_{i}, \mathbf{e}, \omega\right) u\left(c\left(q_{i}, \omega\right)\right) & =\sum_{\ell=1}^{N} \sum_{q_{-\ell}} \sum_{q_{\ell}} \pi^{r}\left(\mathbf{c}, q_{-\ell}, q_{\ell}, \mathbf{e}, \omega\right) \frac{u\left(c\left(q_{\ell}, \omega\right)\right)}{N} \\
& =\sum_{\mathbf{q}} \sum_{\ell=1}^{N} \pi^{r}\left(\mathbf{c}, q_{-\ell}, q_{\ell}, \mathbf{e}, \omega\right) \frac{u\left(c\left(q_{\ell}, \omega\right)\right)}{N} \\
& =\sum_{\mathbf{q}} \pi^{r}(\mathbf{c}, \mathbf{q}, \mathbf{e}, \omega) \sum_{\ell=1}^{N} \frac{u\left(c\left(q_{\ell}, \omega\right)\right)}{N}
\end{aligned}
$$

Substituting this equation into 45 yields the following:

$$
\begin{aligned}
\bar{u}_{i} & \leq \sum_{\mathbf{c}, \mathbf{q}, \mathbf{e}, \omega} \pi^{r}(\mathbf{c}, \mathbf{q}, \mathbf{e}, \omega) \sum_{\ell=1}^{N} \frac{u\left(c\left(q_{\ell}, \omega\right)\right)}{N} \\
& =\sum_{c_{a}, \mu, \mathbf{q}, \mathbf{e}, \omega} \pi^{g}\left(c_{a}, \mu, \mathbf{q}, \mathbf{e}, \omega\right) u\left(\frac{c_{a}(\mathbf{q}, \omega)}{N}\right)
\end{aligned}
$$

Substituting (43) and (44) into the above inequality yields the participation constraint, (22), for the group contract $\pi^{g}$ :

$$
\bar{u}_{i} \leq \sum_{c_{a}, \mu, \mathbf{q}, \mathbf{e}, \omega} \pi^{g}\left(c_{a}, \mu, \mathbf{q}, \mathbf{e}, \omega\right) u\left(\frac{c_{a}(\mathbf{q}, \omega)}{N}\right)
$$


This inequality proves that the candidate group contract, as defined by $(43)$ and $(44)$, satisfies the participation constraint for the group contract, (22).

Now consider the incentive constraints (13) for the relative performance contract $\pi^{r}$ for each $e_{i}, \tilde{e}_{i}$ :

$$
\begin{aligned}
\sum_{\mathbf{c}, \mathbf{q}, \mathbf{e}_{-i}, \omega} \pi^{r}\left(\mathbf{c}, \mathbf{q}, e_{i}, \mathbf{e}_{-i}, \omega\right) u\left(c_{i}^{r}, e_{i}\right) \geq \\
\sum_{\mathbf{c}, \mathbf{q}, \mathbf{e}_{-i}, \omega} \pi^{r}\left(\mathbf{c}, \mathbf{q}, e_{i}, \mathbf{e}_{-i}, s\right) \frac{\operatorname{Pr}\left(\mathbf{q} \mid \tilde{e}_{i}, \mathbf{e}_{-i}, \omega\right)}{\operatorname{Pr}\left(\mathbf{q} \mid e_{i}, \mathbf{e}_{-i}, s\right)} u\left(c_{i}^{r}, \tilde{e}_{i}\right) .
\end{aligned}
$$

Multiplying this constraint by $\frac{1}{N}$ and summing over $i$ yields the following:

$$
\begin{aligned}
\sum_{\mathbf{c}, \mathbf{q}, \mathbf{e}_{-i}, \omega} & \pi^{r}(\mathbf{c}, \mathbf{q}, \mathbf{e}, \omega) \sum_{i=1}^{N} \frac{u\left(c\left(q_{i}, \omega\right), e_{i}\right)}{N} \geq \\
& \sum_{\mathbf{c}, \mathbf{q}, \mathbf{e}_{-i}, \omega} \pi^{r}(\mathbf{c}, \mathbf{q}, \mathbf{e}, \omega) \frac{\operatorname{Pr}\left(\mathbf{q} \mid \tilde{e}_{i}, \mathbf{e}_{-i}, s\right)}{\operatorname{Pr}\left(\mathbf{q} \mid e_{i}, \mathbf{e}_{-i}, s\right)} \sum_{i=1}^{N} \frac{u\left(c\left(q_{i}, \omega\right), \tilde{e}_{i}\right)}{N} .
\end{aligned}
$$

Substituting (43) and (44) into the above inequality yields the incentive constraint, (19), for the group contract $\pi^{g}$ : for each $e_{i}, \tilde{e}_{i}$,

$$
\begin{aligned}
& \sum_{c_{a}, \mathbf{q}, \omega} \pi^{g}\left(c_{a}, \mu, \mathbf{q}, \mathbf{e}, \omega\right) \sum_{i} \mu_{i} u\left(\frac{c_{a}}{N}, e_{i}\right) \geq \\
& \sum_{c_{a}, \mathbf{q}, \omega} \pi^{g}\left(c_{A}, \mu, \mathbf{q}, \mathbf{e}, \omega\right) \frac{\operatorname{Pr}(\mathbf{q} \mid \tilde{\mathbf{e}}, k, s)}{\operatorname{Pr}(\mathbf{q} \mid \mathbf{e}, k, s)} \sum_{i} \mu_{i} u\left(\frac{c_{a}}{N}, \tilde{e}_{i}\right)
\end{aligned}
$$

This inequality proves that the candidate group contract, as defined by (43) and (44), satisfies the incentive constraint for the group contract, 19.

In summary, the candidate group contract, as defined by (43) and (44), is a feasible group contract that generates a weakly larger surplus. Further, the new surplus can be strictly larger if at least one of the incentive constraints is binding. This reasoning implies that if an optimal level of effort under relative performance is not minimal level of effort, then there will be a feasible group contract that generates a strictly larger surplus, with the same utility for all agents.

Proof of Proposition 2. One of the difficulties with this proof is that the incentive compatibility constraints, 19, are not well defined when the denominator in each of these expressions, 
$\operatorname{Pr}(\mathbf{q} \mid \mathbf{e}, k, s)=0$, for some value of $(\mathbf{q}, \mathbf{e}, k, s)$. That case is applicable when idiosyncratic shocks are absent and efforts are identical among agents. This case requires a restatement of the incentive constraints.

For a level of output $\mathbf{q}$ that can be reached only out of equilibrium, i.e., $\operatorname{Pr}\left(\mathbf{q} \mid e_{i}, \mathbf{e}_{-i}, s\right)=$ 0 , there is no loss of generality establishing corresponding consumption at the minimum level, $\underline{\mathbf{c}}$, i.e., $\operatorname{Pr}(\underline{\mathbf{c}} \mid \mathbf{q}, \mathbf{e})=1$, where $\underline{\mathbf{c}}=(\underline{c}, \underline{c})$ is the minimum level of consumption in the grid. The incentive constraints for the relative performance regime can now be reformulated as follows:

$$
\sum_{\mathbf{c}, \mathbf{q}, \mathbf{e}_{-i}, s} \pi^{r}\left(\mathbf{c}, \mathbf{q}, e_{i}, \mathbf{e}_{-\mathbf{i}}, s\right) u\left(c_{i}, e_{i}\right) \geq \sum_{\mathbf{c}, \mathbf{q}, \mathbf{e}_{-i}, s} \Phi\left(\mathbf{c}, \mathbf{q}, \tilde{e}_{i}, \mathbf{e}, s\right) \forall e_{i}, \tilde{e}_{i}
$$

where

$$
\Phi\left(\mathbf{c}, \mathbf{q}, \tilde{e}_{i}, \mathbf{e}, s\right)= \begin{cases}\operatorname{Pr}\left(A_{s}\right) \operatorname{Pr}(\mathbf{e}) \operatorname{Pr}\left(\mathbf{q} \mid \tilde{e}_{i}, \mathbf{e}_{-\mathbf{i}}, s\right) u\left(\underline{c}, \tilde{e}_{i}\right), & \text { when } \operatorname{Pr}\left(\mathbf{q} \mid e_{i}, \mathbf{e}_{-\mathbf{i}}, s\right)=0 \\ \pi^{r}\left(\mathbf{c}, \mathbf{q}, e_{i}, \mathbf{e}_{-\mathbf{i}}, s\right) \frac{\operatorname{Pr}\left(\mathbf{q} \mid \tilde{e}_{i}, \mathbf{e}_{-i}, s\right)}{\operatorname{Pr}\left(\mathbf{q} \mid e_{i}, \mathbf{e}_{-i}, s\right)} u\left(c_{i}, \tilde{e}_{i}\right), & \text { otherwise }\end{cases}
$$

The proof now shows that a contract that solves Program 4 below, which is a relative performance problem without the incentive constraints (46) and $\bar{u}_{i}=\bar{u}$ for all $i$, is also a feasible relative performance contract (solves Program 1). In particular, we show that, a solution to Program 4 satisfies the incentive constraints 46 when idiosyncratic shocks are absent, when arbitrarily high punishment is allowed, and when $\bar{u}_{i}=\bar{u}$ for all $i$.

\section{Program 4.}

$$
\max _{\bar{\pi}^{r}} \sum_{\mathbf{c}, \mathbf{q}, \mathbf{e}, s} \bar{\pi}^{r}(\mathbf{c}, \mathbf{q}, \mathbf{e}, s)\left(q_{1}+q_{2}-c_{1}-c_{2}\right)
$$

subject to constraints (10), 11, 14, and

$$
\sum_{\mathbf{c}, \mathbf{q}, \mathbf{e}, s} \bar{\pi}^{r}(\mathbf{c}, \mathbf{q}, \mathbf{e}, s) u\left(c_{i}, e_{i}\right) \geq \bar{u} \forall i
$$

Let $\bar{\pi}^{r}(\mathbf{c}, \mathbf{q}, \overline{\mathbf{e}}, s)$ be a solution to Program 4 such that effort levels are identical across agents, i.e., $\overline{\mathbf{e}}=\left(\bar{e}_{1}, \ldots, \bar{e}_{N}\right)$ and $\bar{e}_{1}=\ldots=\bar{e}_{N}=\bar{e}$. If the minimal level of effort is adopted in the solution, then the incentive constraints would be trivially satisfied. If any other level of effort $\bar{e}$ is adopted with positive probability, then the incentive constraints 
would be satisfied only because effort affects the distribution of output. Otherwise, the principal could recommend a lower effort level and lower consumption by holding utility constant and increasing the surplus. As a result, there must be some state $\bar{\omega}$ such that for any $\hat{e}<\bar{e}, E(q \mid \bar{e}, k, \bar{\omega})>E(q \mid \hat{e}, k, \bar{\omega})$. Given the absence of idiosyncratic shocks, it must be the case that $f(\bar{q} \mid e, k, \bar{\omega})=1$ and $f(\hat{q} \mid \hat{e}, k, \bar{\omega})=1$ for some $\bar{q}>\hat{q}$. Thus, if $u\left(\hat{c}_{i}, \bar{e}_{i}\right)$ can be set at a sufficiently negative level, then the incentive compatibility constraints (46) will be satisfied. 